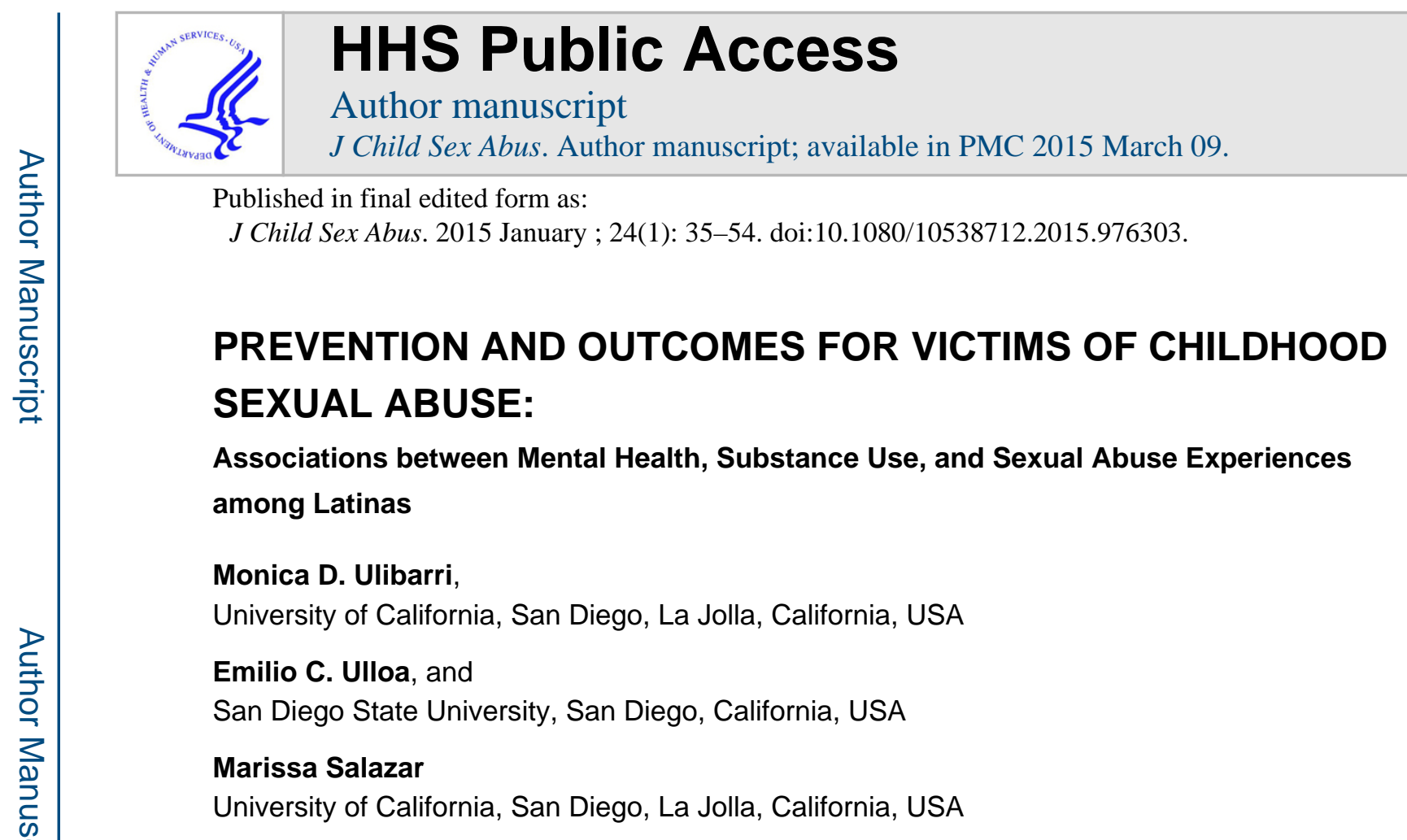

Abstract

This study examined self-reported sexually abusive experiences in childhood and adulthood as correlates of current drug use, alcohol abuse, and depression and posttraumatic stress disorder (PTSD) symptoms. Participants were 204 Latina women 18-34 years old. Results indicated significant relationships between history of sexual abuse (regardless of age of occurrence), depression symptoms, PTSD symptoms, alcohol abuse, and drug use. When examined separately, childhood sexual abuse was associated with symptoms of depression, PTSD, and substance use but not alcohol abuse behaviors. Experiencing sexual abuse in adulthood was associated with symptoms of depression, alcohol abuse behaviors, and substance use but not PTSD symptoms. Structural equation modeling showed that substance use partially mediated the relationship between sexual abuse and mental health outcomes. These findings suggest mental health and substance use services should incorporate treatment for trauma, which may be the root of comorbid mental health and substance use issues.

\title{
Keywords
}

child sexual abuse; adult survivors; substance use; depression; posttraumatic stress disorder; female; Hispanic

Copyright $\odot$ Taylor \& Francis Group, LLC

Address correspondence to Monica D. Ulibarri, Department of Psychiatry, University of California, San Diego, 9500 Gilman Drive, La Jolla, CA 92093-0849. mulibarri@ucsd.edu.

Monica D. Ulibarri, $\mathrm{PhD}$, is a licensed clinical psychologist and assistant professor in the Department of Psychiatry at the University of California, San Diego, and Center on Gender Equity and Health.

Emilio C. Ulloa, $\mathrm{PhD}$, is the director of undergraduate advising and programs in psychology and an associate professor in the Department of Psychology, San Diego State University.

Marissa Salazar, MA, received her master's degree in psychology from San Diego State University and is currently a doctoral student in the Division of Global Public Health, University of California, San Diego. 
Previous research among multiethnic samples of women and girls has demonstrated that survivors of sexual abuse are more likely to develop mental health issues such as symptoms of depression and trauma (Clear, Vincent, \& Harris, 2006; Mennen, 1994; Ullman \& Filipas, 2005), and substance use problems (Cuellar \& Curry, 2007; Vera, Alegria, PattatucciAragon, \& Peña, 2005) compared to those without histories of abuse. However, there is little known about the process linking sexual violence victimization to later substance use and mental health problems (White \& Widom, 2008). In addition, relatively little research has examined the prevalence and circumstances of sexual violence (e.g., childhood sexual abuse, coercive and unwanted sexual experiences, and rape), mental health issues, and co-occurring substance use among Latina women specifically. Given that Latinos are a growing proportion of the U.S. population (U.S. Census Bureau, 2012) who may be at high risk for various forms of violence victimization (Cuevas, Sabina, \& Milloshi, 2012), it is important to understand how such experiences affect this population. In addition, research comparing one cultural group to another may not address issues inherent within one specific cultural group (Hinson, Koverola, \& Morahan, 2002). Therefore, this study will examine one specific ethnic minority group: predominantly Mexican-origin Latinas. Thus far, the majority of research examining sexual violence victimization among Latinas has done so as a subgroup in multiethnic samples (Sciolla et al., 2011; Warner, Alegria, \& Canino, 2012) or has not examined mental health issues and substance use together (Cuevas et al., 2012; Cuevas, Sabina, \& Picard, 2010).

\section{SEXUAL ABUSE AND MENTAL HEALTH ISSUES}

Several cross-sectional and longitudinal studies showed that experiencing sexual abuse, especially during childhood, was significantly associated with mood and anxiety disorder symptoms, even when controlling for previous or co-occurring physical and emotional abuse (Afifi et al., 2008; Roberts, O'Connor, Dunn, \& Golding, 2004; Schilling, Aseltine, \& Gore, 2007; Teicher, Samson, Polcari, \& Andersen, 2009). Research among community samples of ethnic minority women has also documented significant associations between childhood sexual abuse (CSA) and mental health problems during adulthood such as depression (Roosa, Reinholtz, \& Angelini, 1999; Sciolla et al., 2011) and anxiety disorder symptoms (Cuevas et al., 2010; Glover et al., 2010; Warner et al., 2012). To a lesser extent, there has also been research among multiethnic and national samples of women examining the association between sexual violence victimization in adulthood and mental health issues (Bryant-Davis, Chung, \& Tillman, 2009; Cook, Pilver, Dinnen, Schnurr, \& Hoff, 2013; Kaukinen \& Demaris, 2005). The majority of research has focused on childhood sexual violence victimization using multiethnic samples, which is important given that younger age at the time of the event is associated with more debilitating effects (Wyatt et al., 2002). However, not much is known about adulthood sexual violence victimization and mental health outcomes among Latina women specifically. The current study addresses this research gap by providing information about sexual violence victimization in both childhood and adulthood among a community sample of Latina women. 


\section{SEXUAL ABUSE AND SUBSTANCE USE}

Previous research has shown that female survivors of sexual abuse are more likely to have alcohol and drug use problems compared to those without a history of sexual abuse (Molnar, Buka, \& Kessler, 2001). Researchers theorize that substance use may serve as a method of self-medication to cope with sexual abuse victimization and resulting symptoms of depression and posttraumatic stress disorder (PTSD) (Ullman, Filipas, Townsend, \& Starzynski, 2005; Ullman, Najdowski, \& Filipas, 2009; Ullman, Relyea, Peter-Hagene, \& Vasquez, 2013). Therefore, substance use may serve as a mediator of the relationship between sexual abuse victimization and subsequent mental health issues such as depression and PTSD. The theoretical Syndemic Model of Substance Abuse, Intimate Partner Violence, HIV Infection, and Mental Health among Hispanics (Gonzalez-Guarda, Florom-Smith, \& Thomas, 2011) posits that complex health conditions such as substance abuse, violence, HIV risk, depressive symptoms, and underlying socioeconomic disadvantage cluster together forming a syndemic. However, very few studies have formally tested this model. Our study will examine a portion of this syndemic model by studying substance use as a mediator of the relationship between sexual abuse victimization and psychological distress symptoms among Latinas.

\section{PURPOSE}

The purpose of this study was to address a gap in the literature by providing information about the prevalence of sexual abuse experiences in childhood and adulthood and potential correlates such as current symptoms of depression and PTSD, drug use, and alcohol abuse among a traditionally understudied population: predominantly Mexican-origin Latina women. Based on previous research with multiethnic samples of women (Sciolla et al., 2011; Ullman, Townsend, Starzynski, \& Long, 2006) and syndemic theory (GonzalezGuarda, McCabe, Florom-Smith, Cianelli, \& Peragallo, 2011), it was hypothesized that history of sexual abuse would be associated with increased symptoms of depression and PTSD, drug use, and alcohol abuse. In addition, the study examined whether the relationship between sexual abuse and mental health was mediated by substance use.

\section{METHOD}

Participants

Data were obtained from interviews administered as part of a study of human immunodeficiency virus (HIV) risk among Latina women (Ulibarri, 2005). Participants were 204 Latina women recruited from several sites of a program providing nutrition and health education services for low-income women and children in San Diego County. Eligibility criteria were women between the ages 18 to 34 years who self-identify as Latina. Age was restricted from 18 to 34 years because of the original study's focus on HIV risk (Ulibarri, $2005)$. The average age of participants was 25.04 years old $(S D=4.2)$. With regard to ethnic identity, 61\% $(n=124)$ identified themselves as Mexican, 33.8\% $(n=69)$ identified as Mexican-American, and 5.5\% $(n=11)$ identified as Central American, Caribbean, or of other Latin American decent. Both English and Spanish speaking women were included in the sample. Interviews were conducted in the participants' language preference: 53\% ( $n=$ 
108) in Spanish and 47\% $(n=96)$ in English. Although acculturation was not formally measured, generation status in the United States was assessed: 57\% $(n=115)$ were first generation (born in Mexico or Latin America), 34\% ( $n=69)$ were second generation (born in the United States with either parent born in another country), 5\% $(n=10)$ were third generation (born in the United States with all grandparents born in another country), and 5\% $(n=10)$ were fourth generation or beyond (born in the United States with at least one grandparent also born in the United States). Additional demographic information is provided in Table 1.

\section{Procedure}

The study protocol and materials received institutional review board (IRB) approval from San Diego State University's Human Research Protection Program. Flyers providing detailed information about the study and a brief screening questionnaire were available in the lobbies of six San Diego State Foundation WIC (Women Infant and Children Program) clinic sites in San Diego County. The WIC Program is a special food and nutrition education program for low-income, pregnant or postpartum women, infants, and children under five years of age. The recruitment sites were chosen because they would provide access to a large sample of low-income, predominantly Latina, most likely sexually active, women. Women who were interested in participating in the study could take a flyer, fill out the screening questionnaire, and return it to a secured box at the recruitment site. Staff members at each site were available to assist women who had difficulty reading, writing, or understanding the screening questionnaire. All materials were available in both English and Spanish. Women who completed the screening questionnaire and met the eligibility criteria were then contacted by phone to verify their eligibility and consent to participate in the study. A total of 284 completed screening questionnaires were collected. Of those, 204 women $(72 \%)$ met eligibility criteria, and none declined to participate in the study. Participants who completed the interview were mailed a $\$ 20$ gift certificate to a large retail store as recompense.

\section{Measures}

Special consideration for cultural appropriateness and validation with Spanish-speaking populations was given when choosing measures for this study. Measures that were not already available in Spanish were translated into Spanish and back-translated into English by the bilingual, bicultural study team.

Demographics-Demographics were assessed with a series of questions about age, ethnic identity, generation status, employment status, level of education, income, sexual orientation, and marital status.

Sexual abuse-Sexual abuse was assessed using a modified version of the Sexual Experiences Survey (SES, Koss \& Oros, 1982; Roosa, Reyes, Reinholtz, \& Angelini, 1998). Roosa and colleagues (1998) modified the original SES by simplifying the language to be understood by a wider range of educational and reading levels (in both English and Spanish) for a multiethnic sample of women in Arizona. We retained the Roosa and colleagues' language changes for this study. In addition, if women responded that they had ever 
experienced any type of abuse experience, we asked them at what age this event first occurred, their relationship to the perpetrator, whether or not they disclosed the abuse and to whom, and whether or not they felt supported in their disclosure of the abuse. Additional details about the prevalence and context of abuse are published elsewhere (Ulibarri, Ulloa, $\&$ Camacho, 2009). Childhood sexual abuse was defined as any unwanted sexual experiences beginning at age 17 years or younger. Adult sexual abuse was defined as any unwanted sexual experience beginning at or over the age of 18 years. This age of onset distinction allowed for the creation of 3 separate sexual abuse items (Child Sexual Abuse, Adult Sexual Abuse, and Any Sexual Abuse regardless of age of onset). Women were assigned to 1 of 6 categories representing the most severe level of sexual abuse experienced (Boyer \& Fine, 1992; Roosa, Reyes, Reinholtz, \& Angelini, 1998). The 6 levels of severity of abuse were: (a) no sexual abuse, (b) went further sexually than wanted to go, (c) coercion, (d) contact molestation, (e) attempted rape, and (f) rape. Reports of internal consistency (0.74) and test-retest reliability (0.93) for the SES have been good (Koss \& Gidycz, 1985). The Roosa and colleagues studies reported a Cronbach's alpha of 0.84 . This study had a Cronbach's alpha of 0.85 for the 12-item SES.

Depression-Symptoms of depression were assessed using the 20-item Center for Epidemiologic Studies Depression Scale (CES-D; Radloff, 1977). The severity of each symptom is measured by asking for the frequency with which the symptom was experienced during the previous week: response choices range from 0 (rarely or none of the time) to 3 (most or all of the time). Total scale scores can range from 0 to 60. Although a clinical diagnosis of depression cannot be made using the CES-D, high symptom levels can be determined using the traditional cutoff score of 16 or above (Moscicki, Locke, Rae, \& Boyd, 1989; Radloff, 1977). The reliability and validity of the English and Spanish versions of the CES-D have been demonstrated among Latino populations (Grzywacz, Hovey, Seligman, Arcury, \& Quandt, 2006; Moscicki et al., 1989). Alpha coefficients in past studies have ranged from 0.85 to 0.90 depending on community versus clinical samples (Radloff, 1977). Cronbach's alpha for the CES-D in this sample was 0.73 .

PTSD—PTSD symptoms were assessed using an adapted version of the Diagnostic and Statistical Manual Disorders, 4th edition (DSM-IV) checklist (Dausch et al., 2004; Hudziak et al., 1993). The adapted version used in this study asked participants questions related to symptoms associated with a diagnosis of PTSD for traumatic events such as child sexual and physical abuse, life-threatening accidents, and assaults (Dausch et al., 2004). For each of the traumatic events that the participants experienced, they were then asked questions regarding symptoms of PTSD related to the event. The measure can be scored to assess whether the participant fits the DSM-IV criteria for a diagnosis of PTSD for each event by having the required number of symptoms per category, or an overall sum of the number of symptoms experienced can be obtained regardless of diagnosis. We used an overall sum of the number of symptoms for this study, reflecting PTSD symptoms in general, though some of the traumatic events the participants referenced in regards to the PTSD measure were the same as those they endorsed in the SES. 
Alcohol abuse-Alcohol abuse was assessed with six "yes" or "no" items assessing problem drinking behavior associated with abuse (Chambers et al., 2005). Item examples included: "Have you ever felt such a strong desire or urge to drink that you could not resist it?" and "Has your family or friends ever tried to persuade you to stop drinking?" Higher scores represented increased problems with alcohol abuse. Cronbach's alpha for the alcohol abuse items in this sample was 0.70 .

Substance use-Substance use was assessed by asking whether the participant had ever used a series of drugs: marijuana, methamphetamines, cocaine, heroin, or any other drug (then specified by the respondent). If they responded yes to any of the drugs, they were then asked how old they were the first time they used that drug and how often they had used that drug in the past 30 days. Response choices ranged from 0 (rarely) to 4 (almost every day). Current substance use was very low in this sample, so the substance use dependent variable we constructed consisted of the total number of drugs the respondents reported ever using.

\section{Data Analysis}

Nonparametric correlations, a series of hierarchical linear regressions, and Structural Equation Modeling Analyses (SEM) were conducted to test the hypotheses. A path model (a special case of SEM) using observed variables was used to test the study hypotheses using variables of child sexual abuse, adult sexual abuse, drug use, alcohol abuse, posttraumatic stress, and depression. Specific direct and indirect relationships specified in the path model are based on results from linear regressions. Each variable in our model was measured directly with indices. The full path model, as well as the observed results of each path, is displayed in Figure 1.

As seen in Figure 1, both direct and indirect paths between child sexual abuse and depression as well as between adult sexual abuse and depression were hypothesized. The direct causal paths from sexual abuse to depression are included because we hypothesize that the experience of abuse can indeed have effects on depression that are independent of the mediated mechanism. The mediated paths indicate that the associated substance use problems may contribute to depression. Based on initial bivariate analyses, there are only indirect paths indicated between sexual abuse and PTSD symptoms.

\section{RESULTS}

Linear regressions were conducted among the observed variables in the path model. A correlation matrix of study variables is presented in Table 2 . Regression coefficients are presented in Table 3.

\section{Sexual Abuse and Mental Health}

A simple linear regression was performed to determine if depression could be predicted from a history of any sexual abuse. In addition, separate simple regressions were performed to determine if depression could be predicted from both adult and child sexual abuse. Results from bivariate correlations did not yield significant relationships between outcome variables and potential control variables and thus did not warrant the inclusion of other 
variables as controls in the regression equations. Linear regressions revealed significant relationships between any history of sexual abuse (regardless of age of occurrence) and depression $(\beta=0.42, p<.001)$. When examining whether the sexual abuse occurred during childhood or adulthood separately, both remained significantly associated with depression symptoms $(\beta=0.34, p<.001$, and $\beta=0.31, p<.001$, respectively).

A simple linear regression was performed to determine if PTSD could be predicted from a history of any sexual abuse. In addition, separate simple regressions were performed to determine if PTSD could be predicted each from both adult and child sexual abuse. Results from bivariate correlations did not yield significant relationships between outcome variables and potential control variables and thus did not warrant the inclusion of other variables as controls in the regression equations.

There was a significant relationship between any history of sexual abuse and PTSD symptoms $(\beta=0.30, p<.01)$. However, when examined separately, there was a significant association between child sexual abuse and PTSD symptoms $(\beta=0.30, p<.001)$ but not adult sexual abuse and PTSD symptoms $(\beta=0.08, p=$ n.s.).

\section{Sexual Abuse and Substance Use}

A simple linear regression was performed to determine if alcohol abuse could be predicted from a history of any sexual abuse. In addition, separate simple regressions were performed to determine if alcohol abuse could be predicted from both adult and child sexual abuse. In the same manner, a simple linear regression was performed to determine if substance use could be predicted from a history of any sexual abuse. Furthermore, separate simple regressions were performed to determine if substance use could be predicted from both adult and child sexual abuse. Results from bivariate correlations did not yield significant relationships between outcome variables and potential control variables and thus did not warrant the inclusion of other variables as controls in the regression equations. Linear regressions indicated significant relationships between history of sexual abuse and alcohol abuse behaviors $(\beta=0.19, p<.05)$ and substance use $(\beta=0.29, p<.001)$. When examining child and adult sexual abuse separately, there was no significant relationship between child sexual abuse and alcohol abuse $(\beta=0.12, p=$ n.s.); however, there was a moderate significant relationship between adult sexual abuse and alcohol abuse $(\beta=0.17, p<.05)$. With respect to substance use, there was a significant relationship with both child and adult sexual abuse $(\beta=0.22, p<.01$ and $\beta=0.19, p<.01)$, respectively (see Table 3 ).

\section{Structural Equation (Path) Modeling}

The current study tested a path model in order to examine whether the relationship between sexual abuse and mental health was mediated by substance use. The relations in this model were tested using the statistical program MPlus (Version 7; Muthén \& Muthén, 1998-2011). The model specified direct relations from both CSA and adult sexual abuse to depression (see Figure 1) using a maximum likelihood estimation procedure. The model also included indirect paths from CSA to PTSD symptoms, from adult sexual abuse to PTSD symptoms, from CSA to depression symptoms, and from adult sexual abuse to depression symptoms through substance use and alcohol abuse. To determine overall model fit, two descriptive fit 
indices were evaluated: (a) the Standardized Root Mean Residual (SRMR; Hu \& Bentler, 1999), which is sensitive to sample size and becomes more conservative as the number of parameters increases, with values less than .05 indicating optimal model fit and values less than .08 indicating a reasonable model, and (b) the Comparative Fit Index (CFI; Bentler, 1990), which performs well when the sample size is smaller, with values greater than .95 indicating optimal model fit and values greater than .90 indicating reasonable model fit. $\mathrm{Hu}$ and Bentler (1999) suggest a two-index presentation format, which includes the SRMR with either the Non-normed Fit Index (NNFI, also known as the Tucker Lewis Index), Root Mean Square Error of Approximation (RMSEA), or the CFI. CFI is considered the most commonly accepted fit index (McDonald \& Ho, 2002) and recommended as generally acceptable for publication with one time analyses (Schreiber, Stage, King, Nora, \& Barlow, 2006). SRMR is recommended for moderate to small sample sizes, as is the case for the current study.

The overall fit of the model, $\chi^{2}(d f=3)=11.83, p<.05$, SRMR $=.05$, CFI .91 suggested a good fit between the model and the observed data. Our hypothesized model is described graphically in Figure 1. Figure 1 details the conceptual model as well as the observed results. As shown in Figure 1, all of the structural paths composing each direct and indirect effect were statistically significant, with the exception of the path from substance use to depression. Although the theorized model had reasonable fit, it is possible that mental health problems mediate substance abuse symptoms. Therefore, we ran an alternative model in which we reverse the order of our outcomes and mediators. This model fit was not as good (CFI of .89, SRMR of .05), suggesting the directionality of the theorized model may be more appropriate. However, because our data is cross-sectional in nature, we cannot be certain.

\section{DISCUSSION}

Results from this study suggest that a history of sexual abuse has implications for both substance use issues and mental health among Latina women. The results of the regression analyses showed that any sexual abuse was associated with symptoms of depression and PTSD, alcohol abuse, and substance use. Furthermore, when examined in greater depth, child sexual abuse and adult sexual abuse demonstrated different patterns of results. Childhood sexual abuse was associated with symptoms of depression, PTSD, and substance use but not alcohol abuse behaviors. Experiencing sexual abuse in adulthood was associated with symptoms of depression, alcohol abuse behaviors, and substance use but not PTSD symptoms. Perhaps this was due in part to childhood sexual abuse being traumatic enough to have long lasting mental health consequences, although it did not lead to alcohol abuse behaviors in adulthood. Whereas experiencing sexual abuse victimization in adulthood was recent enough to affect alcohol abuse behaviors in addition to symptoms of depression. However, it was surprising that adulthood sexual abuse was not associated with PTSD symptoms as hypothesized.

Nonetheless, the findings from the current study are consistent with research suggesting that women with a history of sexual abuse have higher rates of depression and PTSD (Sciolla et al., 2011; Warner et al., 2012) and are at an increased risk for drug and alcohol abuse 
compared to women who were not abused (Ullman et al., 2005; Ullman et al., 2013). Whereas some research focuses primarily on childhood sexual abuse and others focus on adult sexual abuse victimization, the results of the current study suggest that both may have negative consequences for Latinas regardless of how old they were when they were first sexually abused.

In addition, path analyses were utilized to explore whether and how substance use could serve as a mediator in the relationship between sexual abuse and mental health outcomes. The results suggest the model that best fits the data included both direct and indirect (through alcohol abuse) paths from child and adult sexual abuse to depression. The only path to PTSD symptoms was an indirect one, through substance use. The results support the notion that mental health outcomes associated with sexual abuse are at least partially mediated by substance use. The findings also seem to indicate that the more robust pathway is from sexual abuse to depression symptoms through alcohol abuse, suggesting that for adult Latina women, alcohol may be a particularly widely used maladaptive coping strategy for dealing with the effects of sexual abuse. This is similar to research with ethnically diverse samples that examined mental health variables as mediators of child sexual assault and drug use and alcohol abuse (Ullman et al., 2005; Ullman et al., 2013). However, these studies only examined PTSD (not depression symptoms) and focused on drug and alcohol related problems as the main outcome of interest. Nonetheless, the current study helps shed some light on this underinvestigated area of mental health and sexual violence victimization among Latinas. The findings point to the damaging effects of both child sexual abuse and adult sexual abuse on Latina women.

\section{Implications}

The results from this study have both clinical and research implications. Intervention programs developed for use with Latinas should consider the comorbidity of substance use and mental health problems that are associated with sexual abuse. Our results suggest that both childhood and adulthood sexual abuse victimization may result in negative mental health outcomes and increased substance use. Obtaining a detailed sexual abuse and substance use history may help practitioners better understand their Latina clients' risk for depression and PTSD.

Some research, including the current study, focuses on attempts to understand mental health as the primary outcome of interest with substance use as potential mediators, while others (e.g. Ullman et al., 2005; Ullman et al., 2013) focus on understanding substance abuse as the primary outcome of interest, with mental health as potential mediators. These seemingly oppositional positions may, in fact, highlight the need to explore, longitudinally, the reciprocal nature of mental health and substance use after sexual abuse. Although this study focused on negative mental health outcomes and substance use among sexually abused Latina women, future research is needed to determine if there are other identifiable mediators or moderators in the relationship between sexual abuse and mental health outcomes. In particular, identifying moderators that are protective would be particularly useful in both the treatment and prevention efforts for survivors of sexual abuse. 


\section{Limitations}

Despite the significant findings of this study, a few limitations should be noted. Our findings and past research seem to suggest that it is important to assess multiple types of abuse and abuse victimization at different ages in order to better understand the complexities therein. Although our study assessed both childhood and adulthood sexual abuse, it did not assess multiple forms of violence victimization such as stalking, physical assaults, threats, and witnessed victimization.

Furthermore, since data about sexual abuse were gleaned from a common set of items that ask the respondent to indicate the age when sexual abuse first occurred, the results regarding adult sexual abuse are limited to those women who did not experience child sexual abuse. This is an important limitation because it precludes analyses of the effects of adult sexual abuse on women who may have also experienced child sexual abuse. The nature of this limitation is emphasized when considering that the literature does suggest that victims of child sexual abuse are also likely to experience abuse as adults (Ullman et al., 2009). Future research should examine the complexities of patterns of sexual abuse such as revictimization and continuous abuse across different stages of life.

Third, as with most sexual abuse research, this study was correlational in nature. As a result, causality cannot be inferred. Since experimental designs are not ethically feasible with CSA research, longitudinal studies that assess onset of abuse and onset of symptoms may be a better approach. There have been a few longitudinal, community-based studies that have found a correlation between CSA and maladjustment in adulthood such as depression and suicidal ideation (Dunn, McLaughlin, Slopen, Rosand, \& Smoller, 2013; Fergusson, McLeod, \& Horwood, 2013). Thus, despite the limitations of the current study and most other studies of CSA, our findings are consistent with longitudinal research that suggest robust causal relationships between CSA and maladjustment.

Another limitation of this study is that we used an overall sum of the number of PTSD symptoms rather than sexual abuse event specific PTSD symptoms. Some of the traumatic events the participants referenced in regard to the PTSD measure were the same as those they endorsed in the SES. However, they also referenced other traumatic events in their lives such as physical abuse and life-threatening accidents. Unfortunately, there was not enough power to conduct the analyses specific to PTSD symptoms resulting from the SES events. On the other hand, our use of total number of PTSD symptoms likely better reflects participants' overall symptoms of PTSD and mental health status.

Last, although the research question focuses on Latina women specifically, acculturation was not measured. This makes it difficult to make inferences about the findings with regard to acculturation status. However, we did measure generational status, which is often a proxy for acculturation status and a component of many acculturation scales. Future studies with Latina populations should include measures of acculturation, enculturation, acculturative stress, and other cultural norms in order to better understand possible cultural influences. Although the current study provided information about a specific group of Latinas (predominantly Mexican-origin), it is limited in its ability to speak to how, specifically, Latina cultural values play a role in the sequelae of effects associated with sexual abuse. A 
few researchers have suggested that some Latina cultural values, such as marianismo, respeto, simpatía, and familismo, with their emphasis on female virginity, honor, respect, and harmony within family and interpersonal relationships, may have negative implications for survivors of sexual assault (Castro \& Hernandez, 2004; Ulibarri et al., 2010; Ulibarri et al., 2009). For example, Latinas may be less inclined to disclose sexual abuse, especially if it comes at the hand of a family member. Practitioners may benefit from a better understanding of how specific cultural norms and practices in the Latino culture contribute to the mental health of Latina survivors of sexual assault.

In summary, the pattern of results found in this study raise interesting questions about how Latinas may cope with sexual abuse at different stages of life. Additional prospective research is needed to better understand these patterns and clarify temporal precedence. In addition, further research is needed to learn how the effects of sexual abuse among Latinas can be mitigated.

\title{
ACKNOWLEDGMENTS
}

\begin{abstract}
The authors respectfully acknowledge the participation of all the women in this study. We also thank Jazmine Cuevas, Amber Trigueros-Clemmons, Gina Pimentel, Jenny Chu, Patricia Sanchez, and Vanessa Durand for their work as interviewers and Drs. Carol Nemeroff, Nancy Felipe Russo, and Roger Millsap for their support during the early phases of this research. Special thanks to Sarah Larson and the staff of the San Diego State Foundation WIC for their help with participant recruitment.
\end{abstract}

\section{FUNDING}

This research was funded by an APA Minority Fellowship Program Dissertation Award and a predoctoral position at the Center for Behavioral Epidemiology and Community Health at San Diego State University.

\section{REFERENCES}

Afifi TO, Enns MW, Cox BJ, Asmundson GJG, Stein MB, Sareen J. Population attributable fractions of psychiatric disorders and suicide ideation and attempts associated with adverse childhood experiences. American Journal of Public Health. 2008; 98(5):946-952. [PubMed: 18381992]

Bentler PM. Comparative fit indexes in structural models. Psychological Bulletin. 1990; 107:238-246. [PubMed: 2320703]

Boyer D, Fine D. Sexual abuse as a factor in adolescent pregnancy and child maltreatment. Family Planning Perpsectives. 1992; 24(19):4-11.

Bryant-Davis T, Chung H, Tillman S. From the margins to the center: Ethnic minority women and the mental health effects of sexual assault. Trauma, Violence, \& Abuse. 2009; 10(4):330-357.

Castro, FG.; Hernandez, NT. A cultural perspective on prevention interventions. In: Velasquez, RJ.; Arellano, LM.; McNeill, BW., editors. The handbook of Chicana/o psychology and mental health. Mahwah, NJ: Lawrence Erlbaum Associates; 2004. p. 371-397.

Chambers CD, Hughes S, Meltzer SB, Wahlgren D, Kassem N, Larson S, Hovell MF. Alcohol consumption among low-income pregnant Latinas. Alcoholism: Clinical and Experimental Research. 2005; 29(11):2022-2028.

Clear PJ, Vincent JP, Harris GE. Ethnic differences in symptom presentation of sexually abused girls. Journal of Child Sexual Abuse. 2006; 15(3):79-98. [PubMed: 16893820]

Cook JM, Pilver C, Dinnen S, Schnurr PP, Hoff R. Prevalence of physical and sexual assault and mental health disorders in older women: Findings from a nationally representative sample. The American Journal of Geriatric Psychiatry. 2013; 21(9):877-886. [PubMed: 23567392]

Cuellar J, Curry TR. The prevalence and comorbidity between delinquency, drug abuse, suicide attempts, physical and sexual abuse, and self-mutilation among delinquent Hispanic females. Hispanic Journal of Behavioral Sciences. 2007; 29(1):68-82. 
Cuevas CA, Sabina C, Milloshi R. Interpersonal victimization among a national sample of Latino women. Violence Against Women. 2012; 18(4):377-403. [PubMed: 22761170]

Cuevas CA, Sabina C, Picard EH. Interpersonal victimization patterns and psychopathology among Latino women: Results from the SALAS study. Psychological Trauma: Theory, Research, Practice, and Policy. 2010; 2(4):296-306.

Dausch BM, Compas BE, Beckjord E, Luecken L, Anderson-Hanley C, Sherman M, Grossman C. Rates and correlates of DSM-IV diagnoses in women newly diagnosed with breast cancer. Journal of Clinical Psychology in Medical Settings. 2004; 11(3):159-169.

Dunn EC, McLaughlin KA, Slopen N, Rosand J, Smoller JW. Developmental timing of child maltreatment and symptoms of depression and suicidal ideation in young adulthood: Results from the National Longitudinal Study of Adolescent Health. Depress Anxiety. 2013; 30(10):955-964. [PubMed: 23592532]

Fergusson DM, McLeod GFH, Horwood LJ. Childhood sexual abuse and adult developmental outcomes: Findings from a 30-year longitudinal study in New Zealand. Child Abuse \& Neglect. 2013; 37(9):664-674. [PubMed: 23623446]

Glover DA, Loeb TB, Carmona JV, Sciolla A, Zhang M, Myers HF, Wyatt GE. Childhood sexual abuse severity and disclosure predict posttraumatic stress symptoms and biomarkers in ethnic minority women. Journal of Trauma Dissociation. 2010; 11(2):152-173. [PubMed: 20373204]

Gonzalez-Guarda RM, Florom-Smith AL, Thomas T. A syndemic model of substance abuse, intimate partner violence, HIV infection, and mental health among Hispanics. Public Health Nursing. 2011; 28(4):366-378. [PubMed: 21736615]

Gonzalez-Guarda RM, McCabe BE, Florom-Smith A, Cianelli R, Peragallo N. Substance abuse, violence, HIV, and depression: an underlying syndemic factor among Latinas. Nursing Research and Practice. 2011; 60(3):182-189.

Grzywacz JG, Hovey JD, Seligman LD, Arcury TA, Quandt SA. Evaluating short-form versions of the CES-D for measuring depressive symptoms among immigrants from Mexico. Hispanic Journal of Behavioral Sciences. 2006; 28(3):404-424.

Hinson JV, Koverola C, Morahan M. An empirical investigation of the psychological sequelae of childhood sexual abuse in an adult Latina population. Violence Against Women. 2002; 8(7):816844.

$\mathrm{Hu}$ L, Bentler PM. Cutoff criteria for fit indexes in covariance structure analysis: Conventional criteria versus new alternatives. Structural Equation Modeling. 1999; 6:1-55.

Hudziak JJ, Helzer JE, Wetzel MW, Kessel KB, McGee B, Janca A, Przybeck T. The use of the DSMIII-R Checklist for initial diagnostic assessments. Comprehensive Psychiatry. 1993; 34(6):375383. [PubMed: 8131381]

Kaukinen C, Demaris A. Age at first sexual assault and current substance use and depression. Journal of Interpersonal Violence. 2005; 20(10):1244-1270. [PubMed: 16162488]

Koss MP, Gidycz CA. Sexual Experiences Survey: Reliability and validity. Journal of Consulting and Clinical Psychology. 1985; 53(3):422-423. [PubMed: 3874219]

Koss MP, Oros CJ. Sexual Experiences Survey: A research instrument investigating sexual aggression and victimization. Journal of Consulting and Clinical Psychology. 1982; 50(3):455-457. [PubMed: 7096751]

McDonald RP, Ho M-HR. Principles and practice in reporting structural equation analyses. Psychological Methods. 2002; 7(1):64-82. [PubMed: 11928891]

Mennen FE. Sexual abuse in Latina girls: Their functioning and a comparison with White and African American girls. Hispanic Journal of Behavioral Sciences. 1994; 16(4):475-486.

Molnar BE, Buka SL, Kessler RC. Child sexual abuse and subsequent psychopathology: Results from the National Comorbidity Survey. American Journal of Public Health. 2001; 91(5):753-760. [PubMed: 11344883]

Moscicki EK, Locke BZ, Rae DS, Boyd JH. Depressive symptoms among Mexican Americans: The Hispanic Health and Nutrition Examination Survey. American Journal of Epidemiology. 1989; 130(2):348-360. [PubMed: 2750730]

Muthén, LK.; Muthén, BO. Mplus user's guide. 6th ed.. Los Angeles, CA: Author; 1998-2011. 
Radloff LS. The CES-D Scale: A self-report depression scale for research in the general population. Applied Psychological Measurement. 1977; 1(3):385-401.

Roberts R, O'Connor T, Dunn J, Golding J. The effects of child sexual abuse in later family life: Mental health, parenting and adjustment of offspring. Child Abuse \& Neglect. 2004; 28(5):525545. [PubMed: 15159068]

Roosa MW, Reinholtz C, Angelini PJ. The relation of child sexual abuse and depression in young women: Comparisons across four ethnic groups. Journal of Abnormal Child Psychology. 1999; 27(1):65-76. [PubMed: 10197407]

Roosa MW, Reyes L, Reinholtz C, Angelini PJ. Measurement of women's child sexual abuse experiences: An empirical demonstration of the impact of choice of measure on estimates of incidence rates and of relationships with pathology. Journal of Sex Research. 1998; 35(3):225233.

Schilling EA, Aseltine RH Jr, Gore S. Young women's social and occupational development and mental health in the aftermath of child sexual abuse. American Journal of Community Psychology. 2007; 40(1-2):109-124. [PubMed: 17557204]

Schreiber JB, Stage FK, King J, Nora A, Barlow EA. Reporting structural equation modeling and confirmatory factor analysis results: A review. The Journal of Educational Research. 2006; 99(6): 323-337.

Sciolla A, Glover DA, Loeb TB, Zhang M, Myers HF, Wyatt GE. Childhood sexual abuse severity and disclosure as predictors of depression among adult African-American and Latina women. Journal of Nervous and Mental Disease. 2011; 199(7):471-477. [PubMed: 21716061]

Teicher MH, Samson JA, Polcari A, Andersen SL. Length of time between onset of childhood sexual abuse and emergence of depression in a young adult sample: A retrospective clinical report. Journal of Clinical Psychiatry. 2009; 70(5):684-691. [PubMed: 19358787]

Ulibarri, MD. Latina women's HIV risk study: The relationship between childhood sexual abuse, mental health, and HIV risk (Doctoral dissertation). Tempe, AZ: Arizona State University; 2005. Retrieved from http://libproxy.sdsu.edu/login?url=http://search.ebscohost.com/login.aspx? direct=true $\& \mathrm{db}=$ psyh \&AN=2005-99024-033\&site=ehost-live

Ulibarri MD, Strathdee SA, Lozada R, Magis-Rodriguez C, Amaro H, O’Campo P, Patterson TL. Intimate partner violence among female sex workers in two Mexico-U.S. border cities: Partner characteristics and HIV risk behaviors as correlates of abuse. Psychological Trauma: Theory, Research, Practice, and Policy. 2010; 2(4):318-325.

Ulibarri MD, Ulloa EC, Camacho L. History of childhood sexual abuse among a community sample of Latina women: A descriptive study. Journal of Child Sexual Abuse. 2009; 18(4):405-421. [PubMed: 19842537]

Ullman SE, Filipas HH. Ethnicity and child sexual abuse experiences of female college students. Journal of Child Sexual Abuse. 2005; 14(3):67-89. [PubMed: 16203695]

Ullman SE, Filipas HH, Townsend SM, Starzynski LL. Trauma exposure, posttraumatic stress disorder and problem drinking in sexual assault survivors. Journal of Studies on Alcohol. 2005; 66(5):610 619. [PubMed: 16331846]

Ullman SE, Najdowski CJ, Filipas HH. Child sexual abuse, post-traumatic stress disorder, and substance use: Predictors of revictimization in adult sexual assault survivors. Journal of Child Sexual Abuse: Research, Treatment, \& Program Innovations for Victims, Survivors, \& Offenders. 2009; 18(4):367-385.

Ullman SE, Relyea M, Peter-Hagene L, Vasquez AL. Trauma histories, substance use coping, PTSD, and problem substance use among sexual assault victims. Addictive Behaviors. 2013; 38(6):22192223. [PubMed: 23501138]

Ullman SE, Townsend SM, Starzynski LL, Long LM. Correlates of comorbid PTSD and polysubstance use in sexual assault victims. Violence and Victims. 2006; 21(6):725-743. [PubMed: 17220016]

U.S. Census Bureau. U.S. Census Bureau projections show a slower growing, older, more diverse nation a half century from now. 2012. Retrieved from http://www.census.gov/newsroom/releases/ archives/population/cb12-243.html 
Vera, M.; Alegria, M.; Pattatucci-Aragon, AM.; Peña, M. Childhood sexual abuse and drug use among low-income urban Puerto Rican women. Binghamton, NY: Haworth; 2005.

Warner LA, Alegria M, Canino G. Childhood maltreatment among Hispanic women in the United States: An examination of subgroup differences and impact on psychiatric disorder. Child Maltreatreatment. 2012; 17(2):119-131.

White HR, Widom CS. Three potential mediators of the effects of child abuse and neglect on adulthood substance use among women. Journal of Studies on Alcohol and Drugs. 2008; 69(3): 337-347. [PubMed: 18432375]

Wyatt GE, Myers HF, Williams JK, Kitchen CR, Loeb T, Carmona JV, Presley N. Does a history of trauma contribute to HIV risk for women of color? Implications for prevention and policy. American Journal of Public Health. 2002; 92(4):660-665. [PubMed: 11919068] 


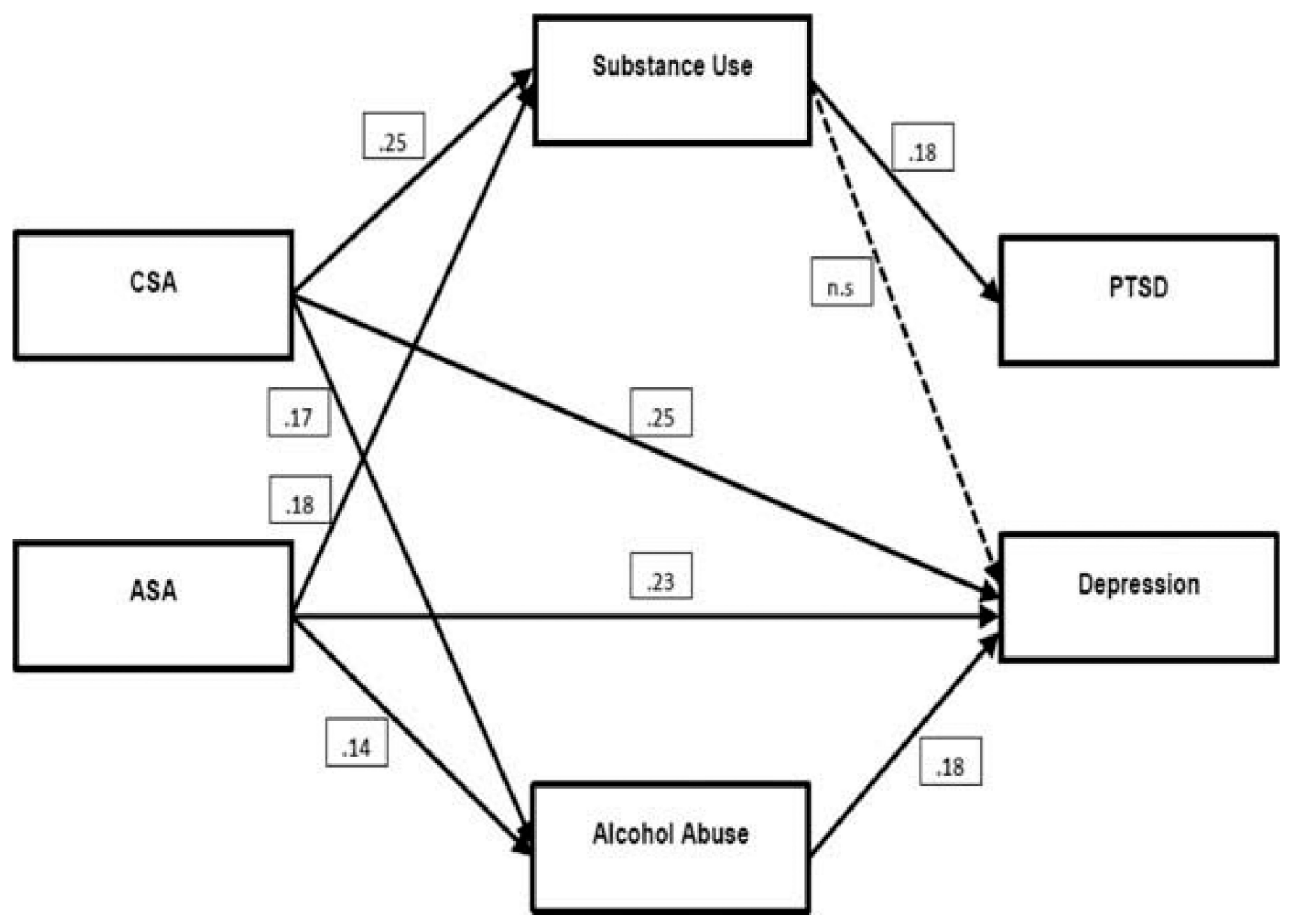

FIGURE 1.

Path model examining child sexual abuse, adult sexual abuse, substance use, alcohol abuse, PTSD symptoms, and depression symptoms and coefficient values for each path. Note:

Unless otherwise noted, all paths are significant at $p<.001$. The overall fit of the model, $\chi^{2}$ $(d f=3)=11.83, p<.05$, SRMR $=.05$, CFI .91 . 


\section{TABLE 1}

\section{Characteristics of the Participants}

\begin{tabular}{|c|c|c|c|c|}
\hline Characteristic & $n$ & $\%$ & $M$ & $S D$ \\
\hline \multicolumn{5}{|l|}{ Demographics } \\
\hline Age & 204 & & 25.04 & 4.2 \\
\hline \multicolumn{5}{|l|}{ Ethnic identity } \\
\hline Mexican & 124 & 61 & & \\
\hline Mexican American & 69 & 33.8 & & \\
\hline Central American & 4 & 2 & & \\
\hline Caribbean & 3 & 1.5 & & \\
\hline Other & 4 & 2 & & \\
\hline \multicolumn{5}{|l|}{ Language preference } \\
\hline Spanish & 108 & 53 & & \\
\hline English & 96 & 47 & & \\
\hline \multicolumn{5}{|l|}{ Generation status } \\
\hline First (born in Mexico/Latin America) & 115 & 56.4 & & \\
\hline Second (born in United States with either parent born in another country) & 69 & 33.8 & & \\
\hline Third (born in United States with all grandparents born in another country) & 10 & 5 & & \\
\hline Fourth generation and beyond (born in United States with at least one grandparent born in United States) & 10 & 5 & & \\
\hline \multicolumn{5}{|l|}{ Education level } \\
\hline No school & 2 & 1 & & \\
\hline 11th grade or lower & 85 & 42 & & \\
\hline High school degree or GED & 70 & 34 & & \\
\hline Some college or trade school & 33 & 16 & & \\
\hline College degree & 14 & 7 & & \\
\hline \multicolumn{5}{|l|}{ Income per month for household } \\
\hline Less than $\$ 500$ & 19 & 9.4 & & \\
\hline$\$ 500-\$ 1,000$ & 43 & 21.2 & & \\
\hline$\$ 1,001-\$ 1,500$ & 44 & 22 & & \\
\hline More than $\$ 1,500$ & 71 & 35 & & \\
\hline Don't know or supported by others & 26 & 12.8 & & \\
\hline Missing & 1 & .5 & & \\
\hline \multicolumn{5}{|l|}{ Sexual preference } \\
\hline Sex always with men & 190 & 95 & & \\
\hline Sex almost always with men & 8 & 4 & & \\
\hline Sex with men and women equally & 2 & 1 & & \\
\hline Sex almost always with women & 0 & 0 & & \\
\hline Sex always with women & 0 & 0 & & \\
\hline \multicolumn{5}{|l|}{ Marital status } \\
\hline Never married/not living with partner & 38 & 18.6 & & \\
\hline Not married/living with partner & 58 & 28.4 & & \\
\hline Married & 87 & 42.6 & & \\
\hline
\end{tabular}




\begin{tabular}{|c|c|c|c|c|}
\hline Characteristic & $n$ & $\%$ & $M$ & $S D$ \\
\hline Separated or divorced & 21 & 10.3 & & \\
\hline \multicolumn{5}{|l|}{ Prevalence and severity of sexual abuse } \\
\hline \multicolumn{5}{|l|}{ Any sexual abuse (regardless of age) } \\
\hline No abuse & 100 & 49 & & \\
\hline Further sexually than wanted & 18 & 9 & & \\
\hline Coercion & 9 & 4 & & \\
\hline Contact molestation & 10 & 5 & & \\
\hline Attempted rape & 15 & 7 & & \\
\hline Rape & 51 & 25 & & \\
\hline \multicolumn{5}{|l|}{ Child sexual abuse } \\
\hline No abuse & 133 & 65 & & \\
\hline Further sexually than wanted & 12 & 6 & & \\
\hline Coercion & 8 & 4 & & \\
\hline Contact molestation & 8 & 4 & & \\
\hline Attempted rape & 5 & 2 & & \\
\hline Rape & 38 & 19 & & \\
\hline \multicolumn{5}{|l|}{ Adult sexual abuse } \\
\hline No abuse & 144 & 71 & & \\
\hline Further sexually than wanted & 10 & 5 & & \\
\hline Coercion & 11 & 6 & & \\
\hline Contact molestation & 6 & 3 & & \\
\hline Attempted rape & 12 & 6 & & \\
\hline Rape & 18 & 9 & & \\
\hline \multicolumn{5}{|l|}{ Mental health and substance use } \\
\hline Number of PTSD symptoms & & & .343 & .476 \\
\hline CES-D (depression symptoms) total & & & 18.98 & 7.79 \\
\hline Alcohol abuse total & & & .629 & 1.15 \\
\hline Substance use total & & & 1.15 & 1.39 \\
\hline
\end{tabular}



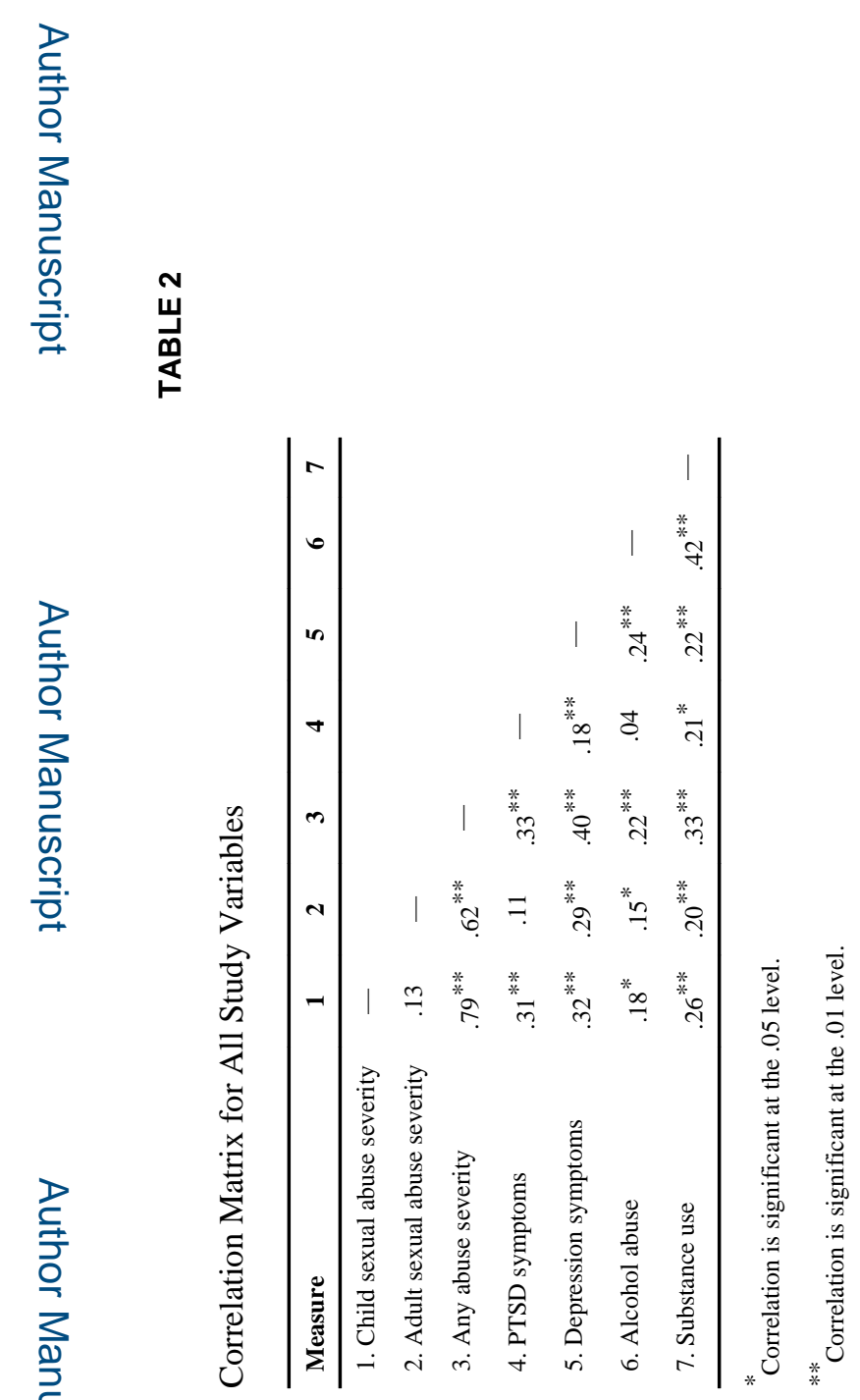
TABLE 3

\section{Linear Regression Results}

\begin{tabular}{llcc}
\hline Dependent variable & Independent variable & $\boldsymbol{\beta}$ & $\boldsymbol{p}$ \\
\hline Depression symptoms & Any sexual abuse & .42 & $<.001$ \\
& Child sexual abuse & .34 & $<.001$ \\
& Adult sexual abuse & .31 & $<.001$ \\
PTSD symptoms & Any sexual abuse & .30 & $<.01$ \\
& Child sexual abuse & .30 & $<.001$ \\
& Adult sexual abuse & .08 & n.s. \\
Alcohol abuse & Any sexual abuse & .19 & $<.05$ \\
& Child sexual abuse & .12 & n.s. \\
& Adult sexual abuse & .17 & $<.05$ \\
& Any sexual abuse & .29 & $<.001$ \\
& Child sexual abuse & .22 & $<.01$ \\
& Adult sexual abuse & .19 & $<.01$ \\
\hline
\end{tabular}

